\title{
Lung cancer mortality of residents living near petrochemical industrial complexes: a meta-analysis
}

\author{
Cheng-Kuan Lin ${ }^{1}$, Huei-Yang Hung ${ }^{2}$, David C. Christiani ${ }^{1,3}$, Francesco Forastiere ${ }^{4}$ and Ro-Ting Lin ${ }^{5^{*}}$ (D)
}

\begin{abstract}
Background: Lung cancer, as the leading cause of cancer mortality worldwide, has been linked to environmental factors, such as air pollution. Residential exposure to petrochemicals is considered a possible cause of lung cancer for the nearby population, but results are inconsistent across previous studies. Therefore, we performed a metaanalysis to estimate the pooled risk and to identify possible factors leading to the heterogeneity among studies.

Methods: The standard process of selecting studies followed the Cochrane meta-analysis guideline of identification, screening, eligibility, and inclusion. We assessed the quality of selected studies using the Newcastle-Ottawa scale. Reported point estimates and 95\% confidence intervals were extracted or calculated to estimate the pooled risk. Air quality standards were summarized and treated as a surrogate of exposure to air pollution in the studied countries. Funnel plots, Begg's test and Egger's test were conducted to diagnose publication bias. Meta-regressions were performed to identify explanatory variables of heterogeneity across studies.

Results: A total of 2,017,365 people living nearby petrochemical industrial complexes (PICs) from 13 independent studied population were included in the analysis. The pooled risk of lung cancer mortality for residents living nearby PICs was 1.03-fold higher than people living in non-PIC areas ( $95 \% \mathrm{Cl}=0.98-1.09)$, with a low heterogeneity among studies $\left(I^{2}=25.3 \%\right)$. Such effect was stronger by a factor of $12.6 \%$ for the year of follow-up started 1 year earlier ( $p$-value $=0.034)$.

Conclusions: Our meta-analysis gathering current evidence suggests only a slightly higher risk of lung cancer mortality among residents living nearby PICs, albeit such association didn't receive statistically significance. Reasons for higher risks of early residential exposure to PICs might be attributable to the lack of or less stringent air pollution regulations.
\end{abstract}

Keywords: Lung cancer, Lung neoplasm, Petrochemical, Refinery, Petroleum, Oil and gas industry, Meta-analysis

\section{Background}

Lung cancer is the leading cause of cancer deaths globally [1]. The Global Burden of Disease Study estimated that 1.7 million people died from lung cancer in 2015 [1]. Although tobacco smoking acts as one of the major risk factors for the disease [2, 3], there is still a considerable fraction of lung cancer mortality that remains unexplained [4]. This is particularly noticeable in many high-income countries, which showed an apparent trend of decrease in

\footnotetext{
*Correspondence: roting@mail.cmu.edu.tw

${ }^{5}$ Department of Occupational Safety and Health, College of Public Health,

China Medical University, 91 Hsueh-Shih Road, Taichung 40402, Taiwan

Full list of author information is available at the end of the article
}

the smoking prevalence [5]. Therefore, research in the past two decades has focused on environmental determinants of lung cancer $[4,6]$.

Petrochemical manufacturing industry, defined as petroleum refining (Standard Industrial Classification code [SIC] 2911) or industrial organic chemicals manufacturing (SIC 2869), involves processes that produce and potentially emit hazardous chemicals into the surrounding air, soil, and water. These petrochemical manufacturing factories are usually clustered in an industrial area together with other manufacturing processes or industry, such as steel, coking, and thermoelectric plants $[7,8]$, and called petrochemical industrial complexes (PIC). Several 
studies have detected environmental air pollutants near petrochemical manufacturing plants [9-12] and also after occasional fire accidents at petrochemical plants [13]. Long-term exposure to the poor air quality, as well as radon, chemicals, and arsenic compounds among residents living near petrochemical manufacturing complexes raised general awareness and the need to understand the possible adverse health effects among nearby residents $[4,14]$.

Several epidemiological studies have explored associations between the PICs and lung cancer risks of nearby people. Given high public concerns of health, the US started several investigations of suspected cancer risks for people living nearby PICs back to the 1970s [15-17]. For example, US white males living in petroleum industry counties had 1.10- to 1.17-fold higher risks of lung cancer mortality than males in other counties [17]. Subsequent studies in Italy and UK also revealed similar results with relative risks of 1.26 and 1.04, respectively, among white females [7, 8]. Fast-growing economies in Asia stimulated by the increasing demand for petrochemicals in manufacturing sectors also faced corresponding increases of lung cancer mortalities among residents nearby PICs [18]. However, several studies reported different results. For instance, Tsai and colleagues reported that male residents living in Louisiana's Industrial Corridor had lower risks of lung cancer compared to other Louisiana citizens, even after adjusting for age [19]. Similarly, Simonsen and colleagues reported that the risk of lung cancer was not elevated significantly in accordance with the residence proximity to the industrial area [20].

Due to the inconsistent results, our study aimed to estimate lung cancer mortality risk associated with the PICs by combining cross-country data from different studies via a systematic review and meta-analysis.

\section{Methods}

Data source and study selection

We selected exclusively articles from PubMed, Cochrane Library, Web of Science, Science Direct, and other sources that published before July 11, 2017. We used "(Lung cancer OR Lung neoplasm) AND (Refinery OR Petroleum OR Petrochemical OR Oil and Gas Industry)" as the search term. Two researchers-HY Hung and RT Lin-selected independently articles that met the inclusion and exclusion criteria as below.

\section{Inclusion and exclusion criteria}

The inclusion criteria were: (1) original articles that clearly defined exposure group as residents living nearby PICs; (2) original articles that clearly defined lung cancer mortality according to International Classification of Diseases (ICD); (3) original articles that reported either confidence intervals (CI), standard errors (SE), or both; and (4) original articles that were written in English and full-texts were available. The exclusion criteria were: (1) studies with subjects overlapped with other publication; (2) studies that focused on occupational exposure in petrochemical plants only; and (3) studies that reported lung cancer incidence only and lack of mortality data.

\section{Review process and data extraction}

Figure 1 shows the selection process of the articles, including four steps: identification, screening, eligibility, and included. First, we identified 1249 articles from library databases and excluded 131 duplicated articles. Second, we screened articles by titles and abstracts. We chose 30 of them as relevant to our study objective for full-text review. Third, we carefully reviewed and checked whether those articles clearly defined exposure and health outcome and also reported estimates and CI or SE. Considering that a study population might appear in different articles, we selected the latest article to avoid bias towards the specific population. Finally, we included seven articles that reported 13 estimates for metaanalysis: three articles reporting sex-specific mortality rate ratios of lung cancer $[7,18,21]$; one article reporting sex-specific age-adjusted mortality rates of industrial corridors and Louisiana, respectively [19]; one article

\begin{tabular}{|c|c|c|}
\hline 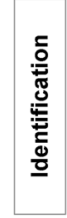 & $\begin{array}{l}\text { Identified articles using keywords } \\
\text { ( } N=1249) \text { : } \\
\text { - PubMed }(N=354) \\
\text { - Cochrane }(N=19) \\
\text { - Web of science }(N=315) \\
\text { - ScienceDirect }(N=557) \\
\text { - } \text { other sources }(N=4)\end{array}$ & \\
\hline & & $\begin{array}{l}\text { Excluded duplicates } \\
(\mathrm{N}=131)\end{array}$ \\
\hline 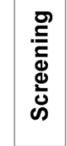 & $\begin{array}{l}\text { Screened potential articles based } \\
\text { on titles and abstracts }(\mathrm{N}=1118) \\
\text { - Original articles } \\
\text { - English articles } \\
\text { - Full-text articles }\end{array}$ & $\begin{array}{l}\text { Excluded after } \\
\text { screening }(\mathrm{N}=1088) \\
\text { - not relevant for } \\
\text { full-text review }\end{array}$ \\
\hline 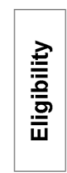 & $\begin{array}{l}\text { Reviewed full texts ( } \mathbf{N}=\mathbf{3 0}) \\
\text { - With mortality rates, estimated } \\
\text { risks, and standard errors or } \\
\text { confidence intervals } \\
\text { - Eligibility of study subjects and } \\
\text { exposure classifications }\end{array}$ & \multirow{2}{*}{$\begin{array}{l}\text { Excluded after } \\
\text { review ( } \mathrm{N}=23 \text { ) } \\
\text { - not match criteria } \\
\text { for quantitative } \\
\text { estimates, such as } \\
\text { lack of confidence } \\
\text { intervals or } \\
\text { standard errors } \\
(\mathrm{N}=17) \\
\text { - overlapped } \\
\text { population }(\mathrm{N}=6)\end{array}$} \\
\hline 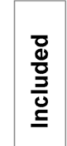 & $\begin{array}{l}\text { Included studies into meta- } \\
\text { analysis }(N=7 ; n=13) \\
\text { - RR }(N=4 ; n=9), O R(N=1 ; n=1), \\
\text { SMR }(N=2 ; n=3)\end{array}$ & \\
\hline $\begin{array}{l}\text { Fig. } 1 \\
\text { for res } \\
n=n u \\
\text { (rate r } \\
\text { morta }\end{array}$ & $\begin{array}{l}\text { v of systematic literature search o } \\
\text { s living nearby petrochemical sites } \\
\text { ar of estimates included into meta- } \\
\text { or risk ratio); OR = odds ratio; SMR = } \\
\text { tio }\end{array}$ & $\begin{array}{l}\text { lung cancer mortality } \\
V=\text { number of studies; } \\
\text { lalysis; } R R=\text { relative risk } \\
\text { standardized }\end{array}$ \\
\hline
\end{tabular}


reporting odds ratios for both sexes combined [22]; one article reporting standardized mortality ratios by sex [8] and another one reporting standardized mortality ratios sex combined [23]. The ratio of Belli's study was regarded as for males in subgroup analysis because male accounted for $84 \%$ of the study group [22].

Since lung cancer mortalities were less than $10^{-3}$ per year [24], we could appropriately interpret estimated odds ratios as relative risks $[25,26]$. The adjusted standardized mortality ratios could be interpreted as relative risks as well because the estimates were derived from the comparison to general population in Rome $[8,27]$.

For the study not reporting CI or SE [19], we estimated the variances and $\mathrm{SE}$ of $\ln R R$ using following equations:

$$
\begin{aligned}
& \operatorname{Var}(\ln R R)=\operatorname{Var}\left(\ln R_{1}+\ln R_{0}\right) \\
&=\operatorname{Var}\left(\ln R_{1}\right)+\operatorname{Var}\left(\ln R_{0}\right) \\
&=\left(\frac{1}{R_{1}}\right)^{2} \times \operatorname{Var}\left(R_{1}\right)+\left(\frac{1}{R_{0}}\right)^{2} \times \operatorname{Var}\left(R_{0}\right) \\
& S E(\ln R R)=\sqrt{\operatorname{Var}(\ln R R)}
\end{aligned}
$$

where $\operatorname{Var}(\ln R R)$ represents the variance of natural $\log$ of relative risks (RRs); $R_{1}$ and $R_{0}$ represents mortality rates of the studied group and the reference group, respectively; and $\mathrm{SE}(\ln R R)$ represents the standard error of natural log of relative risks.

\section{Statistical analysis}

We applied a random-effects model to examine whether there were within- and between-study heterogeneities using the $I^{2}$ test [28]. We set $I^{2}$ less than $10 \%$ as no heterogeneity, $10 \%-30 \%$ as low heterogeneity, $30 \%-60 \%$ as moderate heterogeneity, and more than $60 \%$ as high heterogeneity based on Cochrane handbook [29]. We further did subgroup analysis by different characteristics [30], including sex, location, ethnicity, $\mathrm{PM}_{10}$ standard, latency period (first year of study period more than 20 years after operation year of PICs vs. less or equal to 20 years), and bona fide observation (defined as 10 or more years of observation after 20 years of PIC operations vs. less than 10 years). Then, we applied meta-regressions to investigate the possible factors of heterogeneity, including sex, ethnicity, location, year of publication, and the starting year of follow-up. We also conducted sensitivity analyses to assess the influence of individual study on the overall RR by adding one estimate into the pooled estimates gradually. Finally, we used a funnel plot and the Begg's and Egger's regressions for asymmetry test to examine whether there was publication bias and smallstudy bias. All analyses were performed using the Stata
Software version 11.2 (StataCorp, TX, US). We set the statistical significance level at 0.05, using a two-sided test.

\section{Assessment of data quality}

To assess the risk of bias in each study, the quality of each study was recorded and assessed using the Newcastle-Ottawa Quality Assessment Scale [31]. Records on data quality for each study were reviewed by CK Lin and HY Hung. We evaluated potential bias based on three categories (selection, comparability, and outcome) with eight measurements [31]. Although the discussion on the validity of the Scale remained inconclusive, the reliability of the Scale is quite fair and widely used in meta-analysis [32, 33].

\section{Air quality standards}

Pollutants emitted from PIC might vary over time, likely due to the change of manufacturing process and pollution control technology. Since data on air quality around studied petrochemical areas were limited, we reviewed national or regional ambient air quality standards in studied countries or regions: European Union (EU), Taiwan, and the US. We summarized three air quality standards for studied countries, including total suspended particles (TSP), $\mathrm{PM}_{10}$, and $\mathrm{PM}_{2.5}$ [34-41].

\section{Results}

Table 1 shows the basic characteristics of studies included in our meta-analysis. A total of 13 study groups were extracted, covering around 2,017,365 people living near petrochemical areas in Taiwan, Louisiana in the US, Teesside, West Glamorgan in the UK, and Brindisi, Sicily, and Rome in Italy. Seven out of 13 study groups reported RRs for males, five for females, and one for both sexes combined. The follow-up years ranged widely from 1960 to 2002. Most PICs operated at least 14 years.

Figure 2 shows the pooled estimate of mortality risk for lung cancer among residents living nearby PICs. The estimated overall RR of 1.03 indicated that lung cancer mortality among residences might be associated with exposure to PICs, but it didn't reach statistical significance (95\% CI = 0.98-1.09). Although Belli's study (study ID = H in Fig. 2) reported point estimate of lung cancer risk as high as 3.10 , its broad CI ranging from 0.82 to 11.79 led to the smallest weighting factor of $0.17 \%$ in our metaanalysis. Among the selected studies, the highest weighting factor of $23.35 \%$ (study ID $=\mathrm{K}$ in Fig. 2) indicated that Michelozzi's study on males in Rome contributed to the largest proportion of the pooled estimate, mainly because this study had the narrowest $\mathrm{CI}$. The overall $I^{2}$ was $25.3 \%$, indicating low heterogeneity existed among these studies.

Table 2 shows the results of pooled estimates and 95\% CI by different characteristics, including sex, location, 


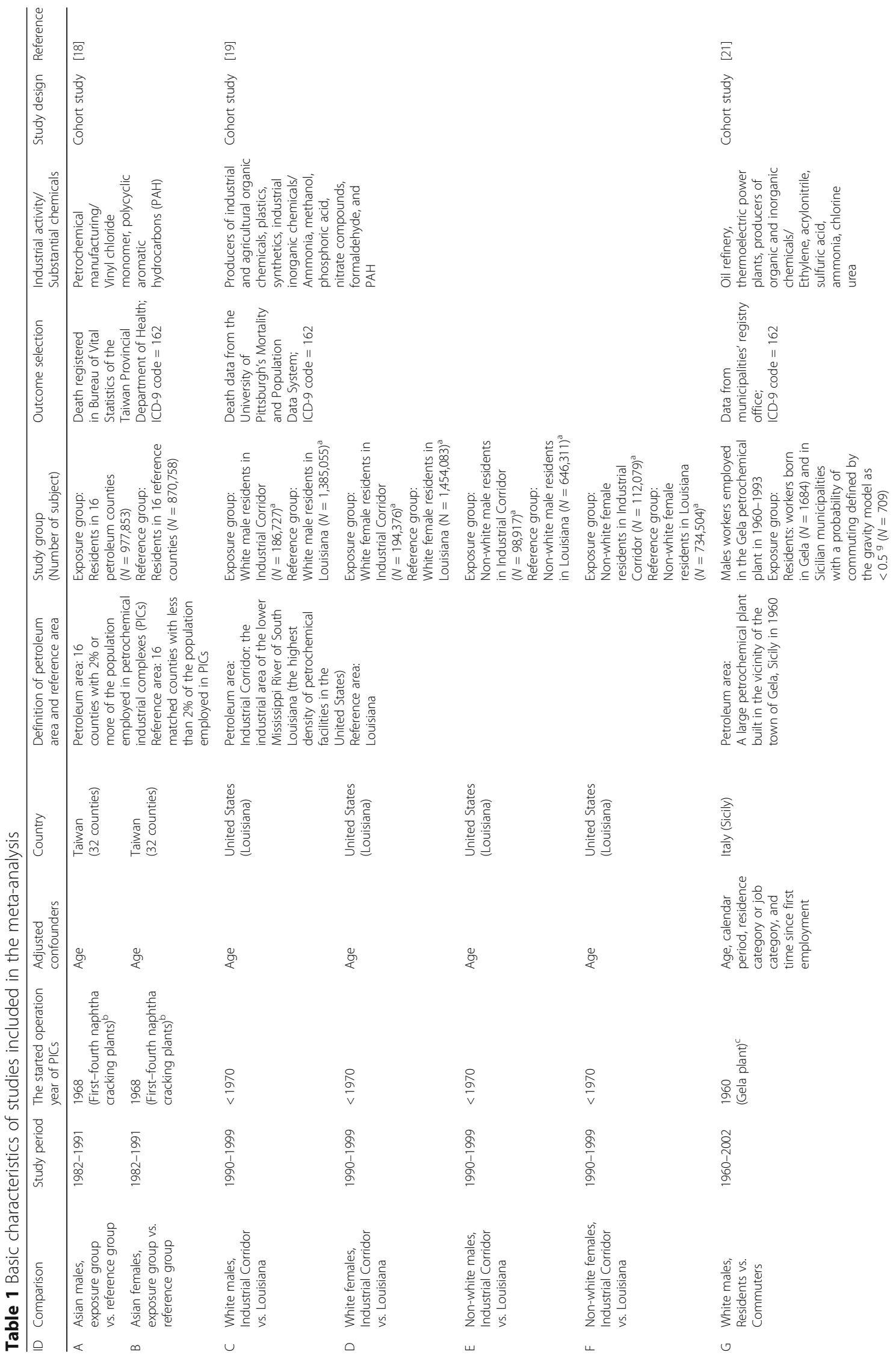




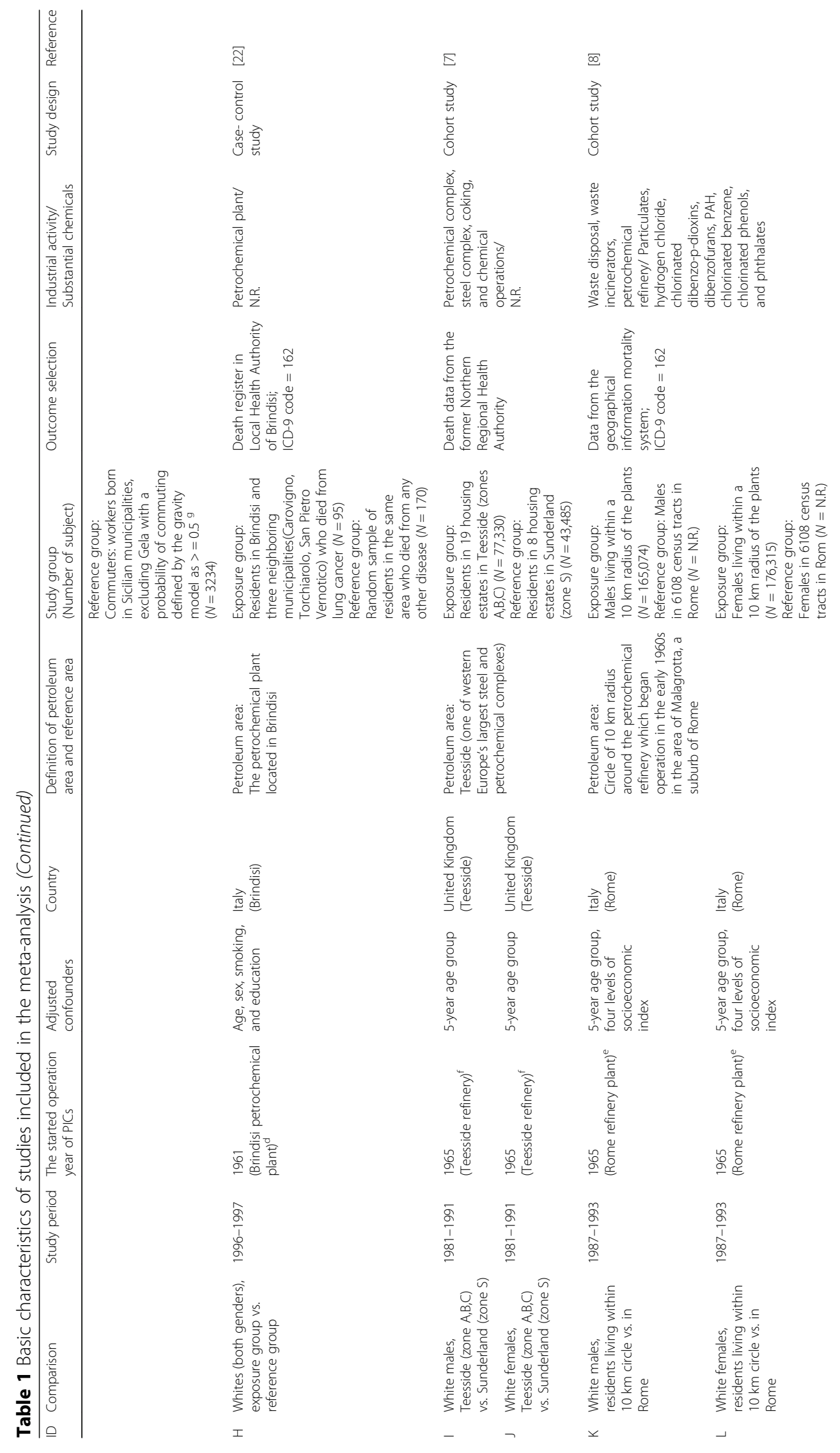




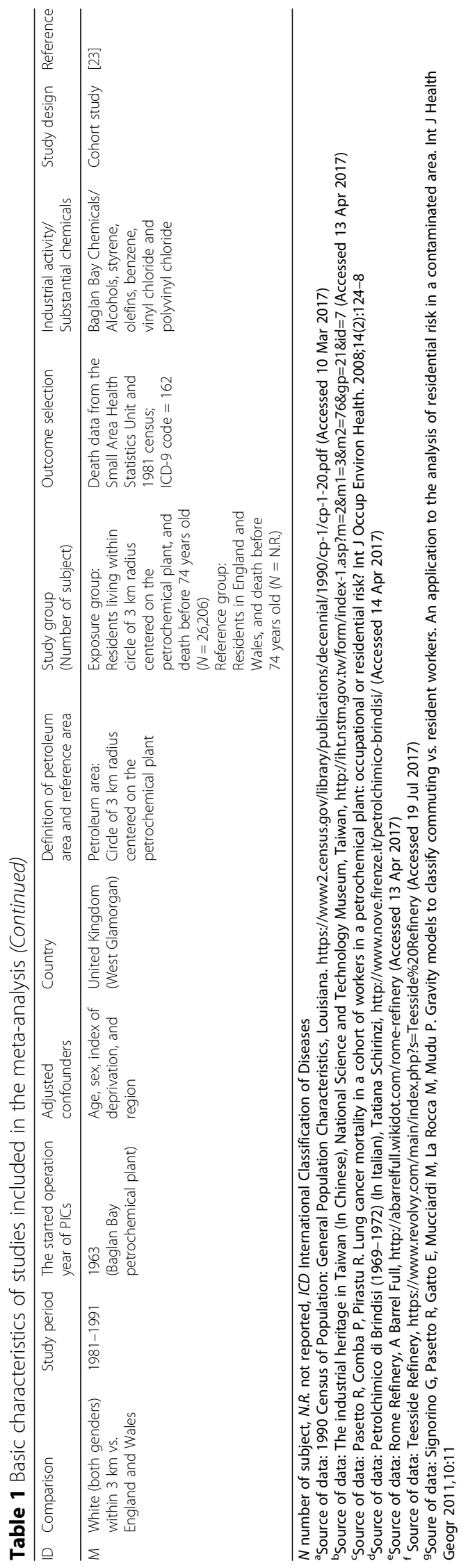




\begin{tabular}{|c|c|c|c|}
\hline \multicolumn{2}{|l|}{ ID (Published year) } & \multirow{2}{*}{$\begin{array}{l}\mathbf{R R}(95 \% \mathrm{Cl}) \\
1.19(0.95,1.49)\end{array}$} & \multirow{2}{*}{$\begin{array}{c}\text { Weight (\%) } \\
5.07\end{array}$} \\
\hline$A(1997)$ & $\rightarrow$ & & \\
\hline B (1997) & $\rightarrow$ & $1.01(0.83,1.23)$ & 6.35 \\
\hline$C(2004)$ & $\rightarrow$ & $0.90(0.77,1.05)$ & 9.00 \\
\hline D (2004) & $\rightarrow$ & $1.02(0.82,1.28)$ & 5.11 \\
\hline$E(2004)$ & $\rightarrow$ & $0.95(0.79,1.15)$ & 6.98 \\
\hline$F(2004)$ & $\rightarrow$ & $1.00(0.73,1.37)$ & 2.81 \\
\hline G (2012) & $\longrightarrow$ & $1.71(1.00,2.93)$ & 1.01 \\
\hline$H(2004)$ & T & $3.10(0.82,11.79)$ & 0.17 \\
\hline I (1998) & $\rightarrow$ & $1.00(0.88,1.13)$ & 12.34 \\
\hline$J(1998)$ & $\rightarrow$ & $1.26(1.04,1.53)$ & 6.37 \\
\hline $\mathrm{K}(1998)$ & - & $1.01(0.95,1.08)$ & 23.35 \\
\hline$L(1998)$ & $\rightarrow$ & $1.04(0.91,1.18)$ & 11.74 \\
\hline M (1995) & $\rightarrow$ & $1.07(0.92,1.24)$ & 9.70 \\
\hline Overall (I-squared $=25.3 \%, p=0.189$ ) & 8 & $1.03(0.98,1.09)$ & 100.00 \\
\hline NOTE: Weights are from random effect & & & \\
\hline
\end{tabular}

Fig. 2 Forest plot of studies on lung cancer risks of residents living nearby petrochemical industrial complexes. RR $=$ relative risk

Table 2 Pooled estimates of relative risks of lung cancer mortality for residents living nearby petrochemical industrial complexes, by different characteristics

\begin{tabular}{|c|c|c|c|c|}
\hline Characteristics & $\mathrm{N}$ & Pooled RR (95\%Cl) & $P^{2}(\%)$ & $p$-value \\
\hline Overall & 13 & $1.03(0.98-1.09)$ & 25.3 & 0.236 \\
\hline \multicolumn{5}{|l|}{ Sex } \\
\hline Males & 7 & $1.02(0.93-1.11)$ & 44.9 & 0.728 \\
\hline Females & 5 & $1.07(0.98-1.16)$ & 0 & 0.137 \\
\hline \multicolumn{5}{|l|}{ Location } \\
\hline Asia & 2 & $1.09(0.93-1.27)$ & 13.6 & 0.311 \\
\hline United States & 4 & $0.95(0.86-1.05)$ & 0 & 0.302 \\
\hline European Union & 7 & $1.07(0.98-1.16)$ & 44.6 & 0.119 \\
\hline \multicolumn{5}{|l|}{ Ethnicity } \\
\hline Asian & 2 & $1.09(0.93-1.27)$ & 13.6 & 0.311 \\
\hline White & 9 & $1.04(0.97-1.12)$ & 41.7 & 0.280 \\
\hline Non-white & 2 & $0.97(0.82-1.13)$ & 0 & 0.666 \\
\hline \multicolumn{5}{|l|}{$\mathrm{PM}_{10}$} \\
\hline $\mathrm{PM}_{10}>150 \mu \mathrm{g} / \mathrm{m}^{3}$ & 4 & $1.12(0.97-1.29)$ & 54.8 & 0.117 \\
\hline $\mathrm{PM}_{10} \leq 150 \mu \mathrm{g} / \mathrm{m}^{3}$ & 9 & $1.01(0.96-1.06)$ & 0 & 0.724 \\
\hline \multicolumn{5}{|l|}{ Latency period } \\
\hline$>20$ years & 9 & $1.00(0.95-1.05)$ & 25.3 & 0.990 \\
\hline$\leq 20$ years & 4 & $1.10(1.00-1.21)$ & 35.9 & 0.056 \\
\hline \multicolumn{5}{|l|}{ bona fide observation } \\
\hline$\geq 10$ years & 6 & $1.01(0.87-1.16)$ & 39.9 & 0.929 \\
\hline$<10$ years & 7 & $1.04(0.99-1.09)$ & 6.8 & 0.115 \\
\hline
\end{tabular}

$N$ numbers of subjects included, $R R$ relative risks ethnicity, $\mathrm{PM}_{10}$ standard, latency period, and bona fide observation. For each characteristic, there was no significant difference among pooled estimates between subgroups based on overlapping 95\% CIs. However, we found a higher risk of lung cancer associated with residential exposure to PICs in the era of looser $\mathrm{PM}_{10}$ standard $(\mathrm{RR}=1.12,95 \% \mathrm{CI}=0.97-1.29$ vs. $\mathrm{RR}=1.01,95 \%$ $\mathrm{CI}=0.96-1.06$ ).

Except for the starting year of follow-up, we did not find any possible heterogeneous factor from the metaregression analysis. The slope of the meta-regression line suggested that for an increment in the starting year of follow-up, the RR of lung cancer would be 0.874-fold lower ( $p$-value $=0.034$, Fig. 3 ).

Figure 4 shows the sensitivity analysis for the effect of individual study on pooled results. We gradually added

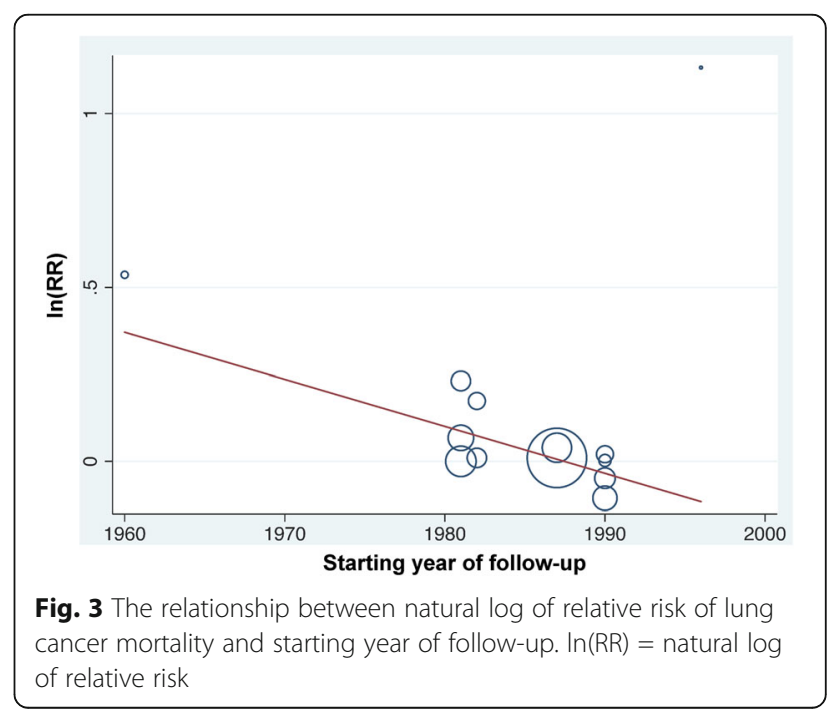




\begin{tabular}{|c|c|c|c|}
\hline ID & Published $\mathrm{J}$ & & RR (95\% Cl) \\
\hline M & 1995 & \begin{tabular}{l|l} 
\\
\end{tabular} & $1.07(0.92,1.24)$ \\
\hline A & 1997 & . & $1.11(0.98,1.25)$ \\
\hline$B$ & 1997 & $\longrightarrow$ & $1.08(0.97,1.20)$ \\
\hline $\mathrm{J}$ & 1998 & $\longrightarrow$ & $1.12(1.02,1.23)$ \\
\hline $\mathrm{K}$ & 1998 & - & $1.07(0.99,1.16)$ \\
\hline I & 1998 & - & $1.05(0.99,1.12)$ \\
\hline $\mathrm{L}$ & 1998 & $\cdot$ & $1.04(0.99,1.09)$ \\
\hline $\mathrm{F}$ & 2004 & - & $1.04(0.99,1.08)$ \\
\hline $\mathrm{D}$ & 2004 & 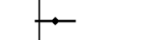 & $1.04(0.99,1.08)$ \\
\hline$E$ & 2004 & {[} & $1.03(0.99,1.08)$ \\
\hline $\mathrm{C}$ & 2004 & $\leftarrow$ & $1.02(0.98,1.06)$ \\
\hline $\mathrm{H}$ & 2004 & $\leftarrow$ & $1.03(0.98,1.08)$ \\
\hline $\mathrm{G}$ & 2012 & $\rightarrow$ & $1.03(0.98,1.09)$ \\
\hline & .7 & 1 & 1.5 \\
\hline \multicolumn{4}{|c|}{ Lung cancer risk } \\
\hline \multicolumn{4}{|c|}{$\begin{array}{l}\text { Fig. } 4 \text { Sensitivity analysis of random effects estimates after adding each } \\
\text { additional study according to the publication year. RR = relative risk }\end{array}$} \\
\hline
\end{tabular}

each study into the sensitivity analysis-from studies published in the earlier period to studies published in the later period. None of them significantly affected the pooled results. There was no significant publication bias among the studies for 13 study groups (Egger's test: $p$ value $=0.059$; Begg's test: $p$-value $=0.051)$. The funnel plot also indicated no asymmetry for the estimates for the 13 study groups was observed (Fig. 5).

Additional file 1 listed details of the quality assessment for cohort and case-control study, respectively. All studies reported sex-specific, age-adjusted point estimates. Some studies further adjusted ethnicity, socioeconomic levels (e.g., school levels, job collars categories, unemployment, number of family members, overcrowding, and ownership of dwellings), or study periods. Four studies had full score

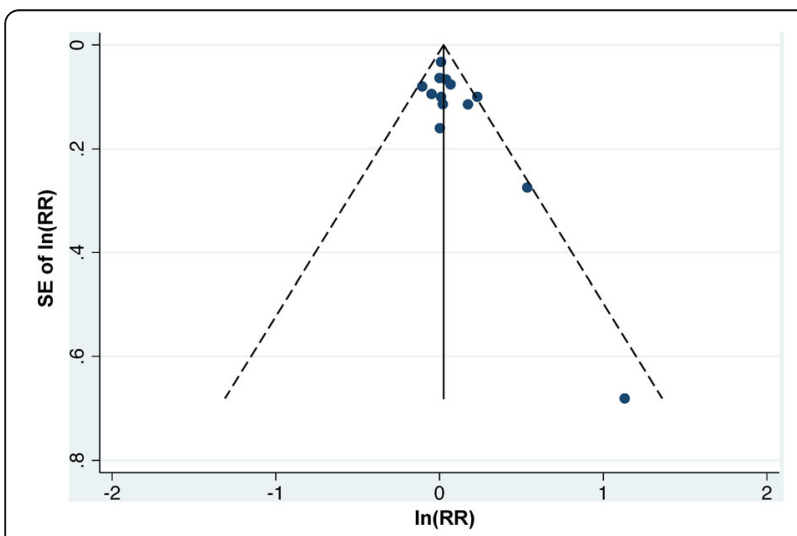

Fig. 5 Funnel plot for lung cancer mortality relative rates associated with residential exposure to petrochemical industrial complexes of the 13 study groups. In(RR) = Natural log of relative risks; SE of $\ln (\mathrm{RR})=$ standard error of natural log of relative risks of nine stars [18, 21-23]; two had 8 out of 9 stars [7, 8]; and one study had seven out of nine stars [19] (see Additional file 2).

Air quality standards in the EU, Taiwan, and the US were summarized in Fig. 6. The earliest standard of ambient air quality was for TSP, followed by $\mathrm{PM}_{10}$ and $\mathrm{PM}_{2.5}$. All countries have set stricter air quality standards over the years. For example, the standard for annual average TSP concentration was $150 \mu \mathrm{g} / \mathrm{m}^{3}$ in the EU in 1983. The EU tightened the regulation by setting up annual $\mathrm{PM}_{10}$ standard at $60 \mu \mathrm{g} / \mathrm{m}^{3}$ in 1996, and then lowering it to $40 \mu \mathrm{g} / \mathrm{m}^{3}$ in 1999 . In 2008 , the EU set up the annual $\mathrm{PM}_{2.5}$ standard at $25 \mu \mathrm{g} / \mathrm{m}^{3}$. Similarly, the US set the annual TSP standard at $75 \mu \mathrm{g} / \mathrm{m}^{3}$ in 1971 , and further tightened the limits to $50 \mu \mathrm{g} / \mathrm{m}^{3}$ in 1987 . In contrast, Taiwan adopted the US's 1971 standard for TSP and $\mathrm{PM}_{10}$ and announced the regulation in 1992, but the limits have not been changed since then.

\section{Discussion}

To our best knowledge, this is the first meta-analysis that estimated the pooled RR of lung cancer mortality for residents living nearby PICs. We aggregated lung cancer risks for 13 study groups from seven published papers in the US, the UK, Italy, and Taiwan. Based on these studies, people living in the PICs had higher lung cancer mortality risks than residents in non-PICs by a factor of 1.03, despite such associations didn't reach statistically significant $(95 \% \mathrm{CI}=0.98-1.09)$. Stratification analysis by different characteristics, such as sex and ethnicity, did not change the magnitude of this association. In contrast, the starting year of follow-up affected the association between lung cancer mortality and exposure to PICs by a factor of 0.874 . That is, the estimated risk of lung cancer mortality was higher among subjects recruited in earlier periods, and the risk decreased by $12.6 \%$ if the year of follow-up started 1 year later.

The scientific evidence of the study is sound and solid from several perspectives. First, the outcome variable was based on pathological samples and/or the ICD-9. Individual data were obtained by linking to governmental database. Second, the large sample size $(n=2,017,365)$ and diverse populations (e.g., by sex, ethnicities, and locations) made the pooled estimate more representative and enhanced the generalizability. Third, by applying the random-effect model, we were able to address the heterogeneity between studies and further reported the pooled effects.

We found higher lung cancer mortality risks among residents near PICs by a factor of 1.03, although this adjusted RR did not reach statistical significance. We identified the following possible limitations of the study. First, the definition of exposure varied slightly between studies. Most studies defined the exposure based on the 


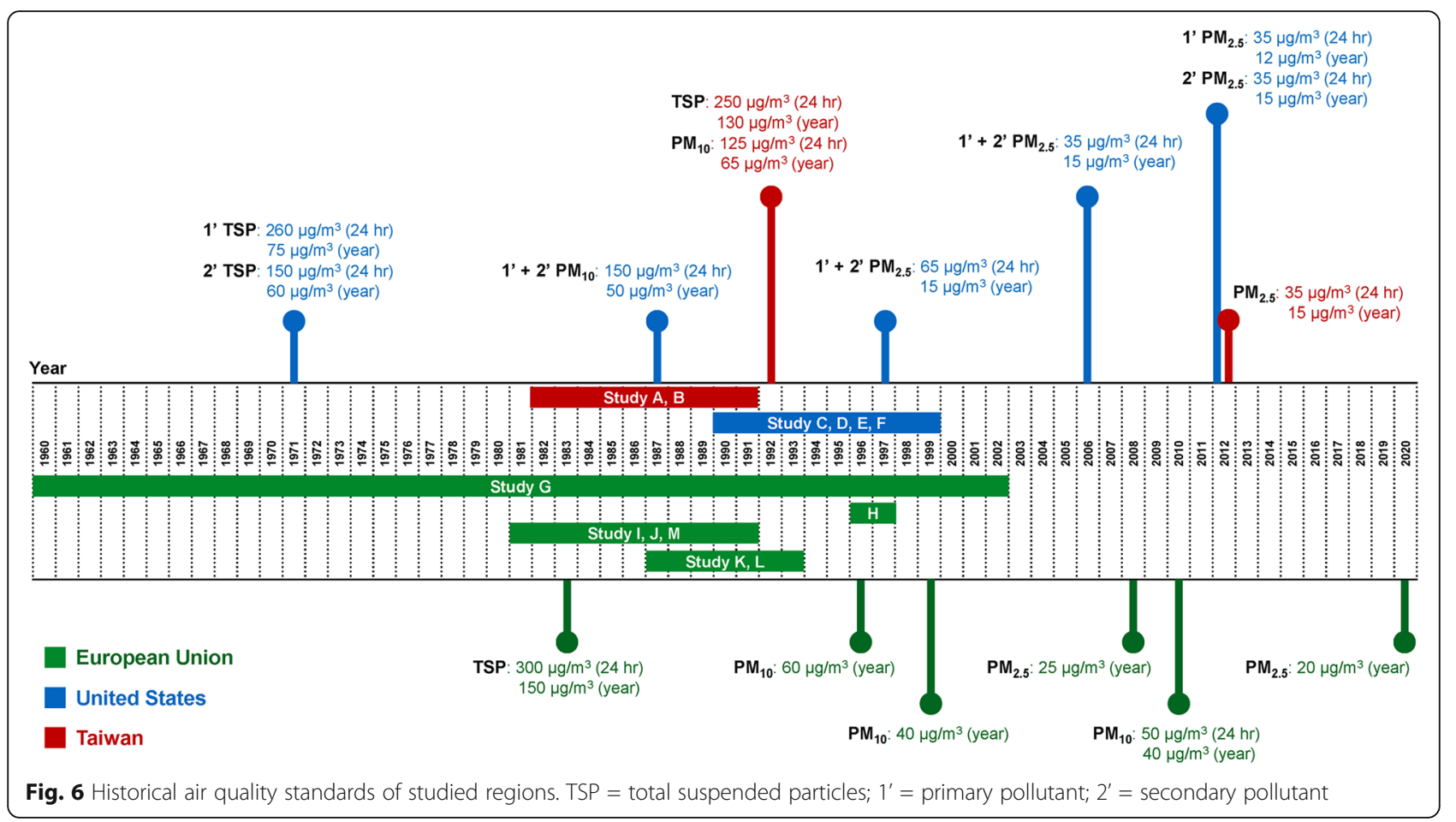

geographical locations or distances of residencies from PIC $[7,8,19,21-23]$, while one study compared the exposed group and reference group by matching job categories in PIC and non-PIC towns [18]. Misclassification of exposure and non-exposure might exist and bias the pooled estimates towards the null. Second, the operation of PICs started as early as 1960 and some PICs are still in operation. Exposure to pollutants emitted from PICs might be quantitatively and qualitatively different in each period. Third, although our subgroup analysis didn't show different risks for residents in different latency periods, still not everyone in the selected studies had sufficient latency periods or adequate follow-up period. The estimations on latency period for lung cancer diagnosis varied widely but usually required approximate years to decades [42, 43]. Inadequate inclusion of residents with insufficient latency might bias the result toward the null in the original studies.

An effective air quality intervention involved a series of steps, including regulatory establishments, pollution reductions, and anticipated improvements in health [44]. Although data on ambient pollution monitoring around PICs in the early periods were very limited and hard to obtain, previous studies have documented pollution reductions could be attributable to changing regulations $[45,46]$. We could reasonably assume that most petrochemical factories followed the local regulations to some extent. Therefore, the historical air quality standards for TSP, $\mathrm{PM}_{10}$, and $\mathrm{PM}_{2.5}$ could reflect the relative trends of exposure to air pollutants emitted from PICs.
Most air quality standards became stricter over the years [34-37, 41]. Such trend partially explains our findings in the heterogeneity regression; that is, studies on populations with earlier exposure to PICs were associated with significantly higher risk of lung cancer mortality.

There are some limitations need to be addressed when interpreting our results. First, not all potential confounders were adjusted in the seven articles, such as smoking, radon exposure, meteorological factors, and socioeconomic status. However, these unadjusted confounders posed an unknown or even lower risk of lung cancer to the exposure group compared to the reference group. For example, the smoking rate of exposure group was lower than the reference group in Bhopal and colleagues' study [7]. Similarly, people lived in the Industrial Corridor had higher socioeconomic status (less unemployed, higher income, and higher educational attainment) compared to the average of Louisiana [19]. Since lower smoking rate and higher neighborhood socioeconomic status were associated with fewer lung cancer incidence $[47,48]$, health benefits from the improvement of socioeconomic status along with industrial development were likely to outweigh the negative effects of exposure to the petrochemical industry. The data on radon exposure, as one of the risk factors of lung cancer, were absent in all selected papers. However, there is no evidence of higher radon exposure in PIC areas than nonPIC ones $[49,50]$. Similarly, seasonal variations of wind directions might either increase or decrease the effect of PIC exposure on residents' health. Since all studies have 
exposure and reference groups from both upwind and downwind locations, subject-selection bias and meteorological effects due to location variance were reduced. Second, studies with available data for meta-analysis were originated from the US, the UK, Italy, and Taiwan. The generalization of the impact of petrochemical industry on lung cancer might be restricted to these countries. However, these four countries represented the majority of countries with the largest petrochemical industries in terms of ethylene production capacity [51], the major base of petrochemicals and a common index to estimate production capacity of a petrochemical company. Third, each PIC might involve other manufacturing processes (such as steel, cocking, and power plants) and the exposure level could also be affected by geographical factors across different countries. Limited by the lack of corresponding exposure data, our findings were not able to address the heterogeneity between PICs. Fourth, certain portion of residents living nearby PICs might risk occupational exposure as well. Some studies have separated the environmental exposure from the occupational exposure (study ID = A, B, G, H) or at least considered job categories in the analysis (study ID $=\mathrm{M}$ ) to reduce the influence of occupational exposure.

\section{Conclusions}

Our meta-analysis gathering current evidence suggests only a slightly higher risk of lung cancer mortality among residents living nearby PICs. Our analysis also underline the role of stringent regulations on improving air quality and reducing the residential exposure to air pollution, which can further contribute to lowering the risk of lung cancer.

\section{Additional files}

Additional file 1: Assessment of study quality using the NewcastleOttawa Quality Assessment Scale for cohort and case-control studies. (DOCX $36 \mathrm{~kb}$ )

Additional file 2: Data quality assessment on the Newcastle-Ottawa Quality Scale. (DOCX $15 \mathrm{~kb}$ )

\section{Abbreviations \\ Cl: Confidence interval; ICD: International Classification of Diseases; \\ PIC: Petrochemical industrial complex; RR: Relative risk; SE: Standard error; \\ SIC: Standard Industrial Classification code; TSP: Total suspended particles}

\section{Acknowledgements}

We are grateful to Professor Chung-Cheng Hsieh of the Department of Epidemiology at the Harvard T.H. Chan School of Public Health for his support for methodology of meta-analysis and Professor Jung-Der Wang of the Department of Public Health, College of Medicine at the National Cheng Kung University for his comments on our response letter. We also acknowledge the great support of Professor Andrea Baccarelli of the Department of Environmental Science at Columbia University on air quality regulations in Europe.

\section{Funding}

This research received no financial support from any agency in the public, commercial, or not-for-profit sectors. No funding source or external agency played any role in study design, data collection, data analysis, data interpretation, or writing of this report.

\section{Availability of data and materials}

The datasets used and/or analyzed during the current study are available from the corresponding author on reasonable request.

\section{Authors' contributions}

CKL contributed to study design, data analysis, reporting results, data interpretation, and writing of the manuscript. HYH contributed to literature reviews, data preparation, data interpretation, and writing of the manuscript. DCC and FF contributed to data interpretation and writing of the manuscript. RTL contributed to study design, literature reviews, data interpretation, and writing of the manuscript. All authors read and approved the final manuscript.

Ethics approval and consent to participate

Not applicable.

Consent for publication

Not applicable.

\section{Competing interests}

The authors declare that they have no competing interests.

\section{Publisher's Note}

Springer Nature remains neutral with regard to jurisdictional claims in published maps and institutional affiliations.

\section{Author details}

${ }^{1}$ Department of Environmental Health, Harvard T.H. Chan School of Public Health, 665 Huntington Avenue, Building 1, Room 1401, Boston, MA 02115, USA. ${ }^{2}$ Department of General Medicine, Kaohsiung Medical University Hospital, No. 100, Tzyou 1st Road, Kaohsiung 807, Taiwan. ${ }^{3}$ Department of Epidemiology, Harvard T.H. Chan School of Public Health, 665 Huntington Avenue, Building 1, Room 1401, Boston, MA 02115, USA. ${ }^{4}$ Department of Epidemiology Lazio Regional Health Service, Via Cristoforo Colombo, 112 Rome, Italy. ${ }^{5}$ Department of Occupational Safety and Health, College of Public Health, China Medical University, 91 Hsueh-Shih Road, Taichung 40402, Taiwan.

Received: 26 May 2017 Accepted: 21 September 2017

Published online: 26 September 2017

\section{References}

1. Wang H, Naghavi M, Allen C, Barber RM, Bhutta ZA, Carter A, et al. Global, regional, and national life expectancy, all-cause mortality, and cause-specific mortality for 249 causes of death, 1980-2015: a systematic analysis for the Global Burden of Disease Study 2015. Lancet. 2016;388(10053):1459-544.

2. Doll R, Peto R, Boreham J, Sutherland I. Mortality in relation to smoking: 50 years' observations on male British doctors. Br Med J. 2004;328(7455):1519-28.

3. Hecht SS. Tobacco smoke carcinogens and lung cancer. J Natl Cancer Inst. 1999;91(14):1194-210.

4. Field RW, Withers BL. Occupational and environmental causes of lung cancer. Clin Chest Med. 2012;33(4):681-703.

5. Bilano V, Gilmour S, Moffiet T, d'Espaignet ET, Stevens GA, Commar A, et al. Global trends and projections for tobacco use, 1990-2013: an analysis of smoking indicators from the WHO Comprehensive Information Systems for Tobacco Control. Lancet. 2015;385(9972):966-76.

6. Dockery DW, Pope CA, Xu XP, Spengler JD, Ware JH, Fay ME, et al. An association between air pollution and mortality in six U.S. cities. N Engl J Med. 1993;329(24):1753-9.

7. Bhopal RS, Moffatt S, Pless-Mulloli T, Phillimore PR, Foy C, Dunn CE, et al. Does living near a constellation of petrochemical, steel, and other industries impair health? Occup Environ Med. 1998;55(12):812-22.

8. Michelozzi P, Fusco D, Forastiere F, Ancona C, Dell'Orco V, Perucci CA. Small area study of mortality among people living near multiple sources of air pollution. Occup Environ Med. 1998;55(9):611-5. 
9. Na K, Kim YP, Moon KC, Moon I, Fung K. Concentrations of volatile organic compounds in an industrial area of Korea. Atmos Environ. 2001;35(15):2747-56.

10. Yuan $\mathrm{TH}$, Chio $\mathrm{CP}$, Shie $\mathrm{RH}$, Pien $\mathrm{WH}$, Chan CC. The distance-to-source trend in vanadium and arsenic exposures for residents living near a petrochemical complex. J Expo Sci Environ Epidemiol. 2016;26(3):270-6.

11. Cetin E, Odabasi M, Seyfioglu R. Ambient volatile organic compound (VOC) concentrations around a petrochemical complex and a petroleum refinery. Sci Total Environ. 2003;312(1-3):103-12

12. Kalabokas PD, Hatzianestis J, Bartzis JG, Papagiannakopoulos P. Atmospheric concentrations of saturated and aromatic hydrocarbons around a Greek oil refinery. Atmos Environ. 2001;35(14):2545-55.

13. Shie RH, Chan CC. Tracking hazardous air pollutants from a refinery fire by applying on-line and off-line air monitoring and back trajectory modeling. J Hazard Mater. 2013;261:72-82.

14. Downey L, Van Willigen M. Environmental stressors: the mental health impacts of living near industrial activity. J Health Soc Behav. 2005;46(3):289-305.

15. Blot WJ, Fraumeni JFJr. Geographic patterns of lung cancer: industrial correlations. Am J Epidemiol 1976;103(6):539-550.

16. Gottlieb MS, Pickle LW, Blot WJ, Fraumeni JFJr. Lung cancer in Louisiana: death certificate analysis. J Natl Cancer Inst 1979;63(5):1131-1137.

17. Blot WJ, Brinton LA, Fraumeni JF Jr, Stone BJ. Cancer mortality in U.S. counties with petroleum industries. Science. 1977;198(4312):51-3.

18. Yang CY, Chiu HF, Chiu JF, Kao WY, Tsai SS, Lan SJ. Cancer mortality and residence near petrochemical industries in Taiwan. J Toxicol Environ Health. 1997;50(3):265-73.

19. Tsai SP, Cardarelli KM, Wendt JK, Fraser AE. Mortality patterns among residents in Louisiana's industrial corridor, USA, 1970-99. Occup Environ Med. 2004;61(4):295-304

20. Simonsen N, Scribner R, Su L, Williams D, Luckett B, Yang T, et al. Environmental exposure to emissions from petrochemical sites and lung cancer: the lower Mississippi interagency cancer study. J Environ Public Health. 2010;2010:759645.

21. Pasetto R, Zona A, Pirastu R, Cernigliaro A, Dardanoni G, Addario SP, et al. Mortality and morbidity study of petrochemical employees in a polluted site. Environ Health. 2012;11:34.

22. Belli S, Benedetti M, Comba P, Lagravinese D, Martucci V, Martuzzi M, et al Case-control study on cancer risk associated to residence in the neighbourhood of a petrochemical plant. Eur J Epidemiol. 2004;19(1):49-54.

23. Sans S, Elliott P, Kleinschmidt I, Shaddick G, Pattenden S, Walls P, et al. Cancer incidence and mortality near the Baglan Bay petrochemical works, South Wales. Occup Environ Med. 1995;52(4):217-24.

24. United States Cancer Statistics: 1999-2013. Incidence and Mortality Web-based Report https://nccd.cdc.gov/uscs/toptencancers.aspx. Accessed 5 Apr 2017.

25. Tsuang MT, Hsieh CC, Fleming JA. Appendix: odds ratio and its interpretation in case-control studies. In: Hsu LKG, Hersen M, editors. Research in psychiatry. US: Springer; 1992. p. 125-32. Accessed 5 Apr 2017.

26. Schmidt $\mathrm{CO}$, Kohlmann T. When to use the odds ratio or the relative risk? Int J Public Health. 2008;53(3):165-7.

27. Symons MJ, Taulbee JD. Practical considerations for approximating relative risk by the standardized mortality ratio. J Occup Med. 1981;23(6):413-6.

28. Higgins JP, Thompson SG, Deeks JJ, Altman DG. Measuring inconsistency in meta-analyses. Br Med J. 2003;327(7414):557-60.

29. Jonathan J Deeks, Julian PT Higgins, Altman DG. Identifying and measuring heterogeneity. In: Julian PT Higgins, Green S, editors. Cochrane handbook for systematic reviews of interventions version 5.1.0. 2011. http://handbook5-1.cochrane.org/. Accessed 5 Apr 2017.

30. Schabath MB, Cress D, Munoz-Antonia T. Racial and Ethnic Differences in the Epidemiology and Genomics of Lung Cancer. Cancer Control. 2016;23(4):338-46.

31. The Newcastle-Ottawa Scale (NOS) for assessing the quality of nonrandomised studies in meta-analyses. http://www.ohri.ca/programs/clinical_epidemiology/ oxford.asp. Accessed 5 Apr 2017.

32. Hootman JM, Driban JB, Sitler MR, Harris KP, Cattano NM. Reliability and validity of three quality rating instruments for systematic reviews of observational studies. Res Synth Methods. 2011:2(2):110-8.

33. Hartling L, Hamm M, Milne A, Vandermeer B, Santaguida PL, Ansari M, et al. Validity and inter-rater reliability testing of quality assessment instruments [internet]. In: Introduction. Agency for Healthcare Research and Quality: Rockville, MD; 2012.

34. Particulate matter (PM) standards-table of historical PM NAAQS. https:// www3.epa.gov/ttn/naaqs/standards/pm/s_pm_history.html. Accessed 14 Apr 2017.
35. Air quality standards (In Chinese). http://law.moj.gov.tw/LawClass/LawAll. aspx?PCode=00020007. Accessed 14 Apr 2017.

36. European Union. Ambient air quality and cleaner air for Europe (Directive 2008/50/EC). http://eur-lex.europa.eu/legal-content/EN/TXT/PDF/?uri=CELEX: 32008L0050\&from=en. Accessed 14 Apr 2017.

37. European Union. Limit values for sulphur dioxide, nitrogen dioxide and oxides of nitrogen, particulate matter and lead in ambient air (Directive 1999/30/EC). http://eur-lex.europa.eu/legal-content/EN/TXT/PDF/?uri=CELEX: 31999L0030\&from=EN. Accessed 14 Apr 2017.

38. Decreto Legislativo 13 Agosto 2010, n.155 (In Italian). http://www. minambiente.it/normative/dlgs-13-agosto-2010-n-155-attuazione-delladirettiva-200850ce-relativa-alla-qualita. Accessed 17 Apr 2017.

39. Decreto Ministeriale 2 Aprile 2002 (In Italian). http://www.gazzettaufficiale.it/ atto/serie_generale/caricaDettaglioAtto/originario?atto. dataPubblicazioneGazzetta=2002-04-13\&atto.codiceRedazionale= 002G0089\&elenco30giorni=false. Accessed 17 Apr 2017.

40. Decreto Ministeriale 25 Novembre 1994 (In Italian). http://www. gazzettaufficiale.it/eli/id/1994/12/13/094A7814/sg. Accessed 17 Apr 2017.

41. Decreto del Presidente del Consiglio dei ministri 28.03.1983 (In Italian). http://www.arpab.it/aria/normativa/D.P.C.M.28marzo1983.pdf. Accessed 17 Apr 2017

42. Howard J: Minimum latency \& types or categories of cancer. In World Trade Center Health Program 2015.

43. Weiss W. Cigarette smoking and lung cancer trends. A light at the end of the tunnel? Chest. 1997;111(5):1414-6.

44. van Erp AM, Kelly FJ, Demerjian KL, Pope CA, Cohen AJ. Progress in research to assess the effectiveness of air quality interventions towards improving public health. Air Qual Atmos Health. 2011;5(2):217-30.

45. Hedley AJ, Wong C-M, Thach TQ, Ma S, Lam T-H, Anderson HR. Cardiorespiratory and all-cause mortality after restrictions on sulphur content of fuel in Hong Kong: an intervention study. Lancet. 2002;360(9346):1646-52.

46. Clancy L, Goodman P, Sinclair H, Dockery DW. Effect of air-pollution control on death rates in Dublin, Ireland: an intervention study. Lancet. 2002;360(9341):1210-4.

47. Hystad P, Carpiano RM, Demers PA, Johnson KC, Brauer M. Neighbourhood socioeconomic status and individual lung cancer risk: evaluating long-term exposure measures and mediating mechanisms. Soc Sci Med. 2013;97:95-103.

48. Sidorchuk A, Agardh EE, Aremu O, Hallqvist J, Allebeck P, Moradi T. Socioeconomic differences in lung cancer incidence: a systematic review and meta-analysis. Cancer Causes Control. 2009;20(4):459-71.

49. Catalano R, Immè G, Mangano G, Morelli D, Tazzer AR. Indoor radon survey in Eastern Sicily. Radiat Meas. 2012;47(1):105-10.

50. Dubois G. An overview of radon surveys in Europe. European Communities: In. Italy; 2005.

51. Nakamura D. Ethylene capacity rising, margins continue to suffer. Oil Gas J. 2002;100(10):66-79.

\section{Submit your next manuscript to BioMed Central and we will help you at every step:}

- We accept pre-submission inquiries

- Our selector tool helps you to find the most relevant journal

- We provide round the clock customer support

- Convenient online submission

- Thorough peer review

- Inclusion in PubMed and all major indexing services

- Maximum visibility for your research

Submit your manuscript at www.biomedcentral.com/submit

Biomed Central 